\title{
INFLUENCIA DA UMIDADE E TEMPERATURA AMBIENTE NO PROCESSO DE SOPRO DO POLI (TEREFTALATO DE ETILENO)
}

\section{THE INFLUENCE OF AMBIENT TEMPERATURE AND HUMID IN THE BLOW MOLDING PROCESS OF POLY (ETHYLENE TEREPHTHALATE)}

\author{
L. W. M. CRUZ ${ }^{1}$, G. C. da SILVA ${ }^{1}$ e T. J. de ALMEIDA ${ }^{1}$ \\ ${ }^{1}$ Pontifícia Universidade Católica de Minas Gerais, Brasil \\ E-mail: leandrowmc@outlook.com
}

\author{
article info \\ Article history: \\ Palavras-Chave: Poli (Tereftalato de Etileno); Processo de sopro; Temperatura ambiente; Umidade \\ Received 2017-09-04 \\ Accepted 2017-11-20 \\ ambiente. \\ Keywords: Poly (Ethylene Terephthalate); Blow molding process; Ambient temperature; Ambient \\ humid.
}

Available online 2017-12-20

RESUMO: O Poli (Tereftalato de Etileno), mais conhecido pela sigla PET, é um dos polímeros de engenharia mais utilizado na produção embalagens, principalmente de frascos. A produção de garrafas de refrigerante, por exemplo, consiste em dois processos: injeção e sopro. É notável que o processo de injeção de PET seja afetado pela umidade ambiente, pois diversas injetoras possuem um secador no próprio silo de alimentação do equipamento. Desta forma, buscou-se avaliar se as condições ambientes também exerciam alguma influência no processo de sopro do PET. A análise foi realizada de forma amostral em dias diferentes, com condições ambientes diferentes e dentro da empresa Brasiaço Indústria e Comércio Ltda. Foi observado que apenas uma das condições ambientes afeta o processo de sopro de PET. Portanto, foi desenvolvido e proposto um método para correlacionar tal condição ambiente aos parâmetros do processo de sopro.

ABSTRACT: The Poly (Ethylene Terephthalate), commonly called PET, is one from the most used engeneer polymer to product wrapping, mainly containers. For instance, the soda bottle poduction consist in two process: injection molding and blow molding. Is apparent that the PET injection molding is affected by ambient humid, so some injection molding machine have a dryer at the own hopper. This research was tried to evaluate if the ambient conditions also exerted some influence in the blow molding of PET. The analysis was performed in a sample manner on different days, with different ambient conditions and within the Brasiaço Indústria $e$ Comércio Ltda. It was observed that just one ambient conditions affects the blow molding of PET. So, a method was developed and proposed to correlate such ambient condition to the parameters of the blowing process.

\section{INTRODUÇÃO}

Os polímeros são materiais que possuem características mecânicas peculiares, pois o comportamento desses materiais é altamente dependente das condições de temperatura e do intervalo de tempo no qual o mesmo é solicitado. Desta forma, o comportamento de um polímero não pode ser simplesmente relacionado por uma constante de proporcionalidade, como o módulo de elasticidade do aço e de outros metais. A Figura 1 ilustra o comportamento de um polímero em função da temperatura. 


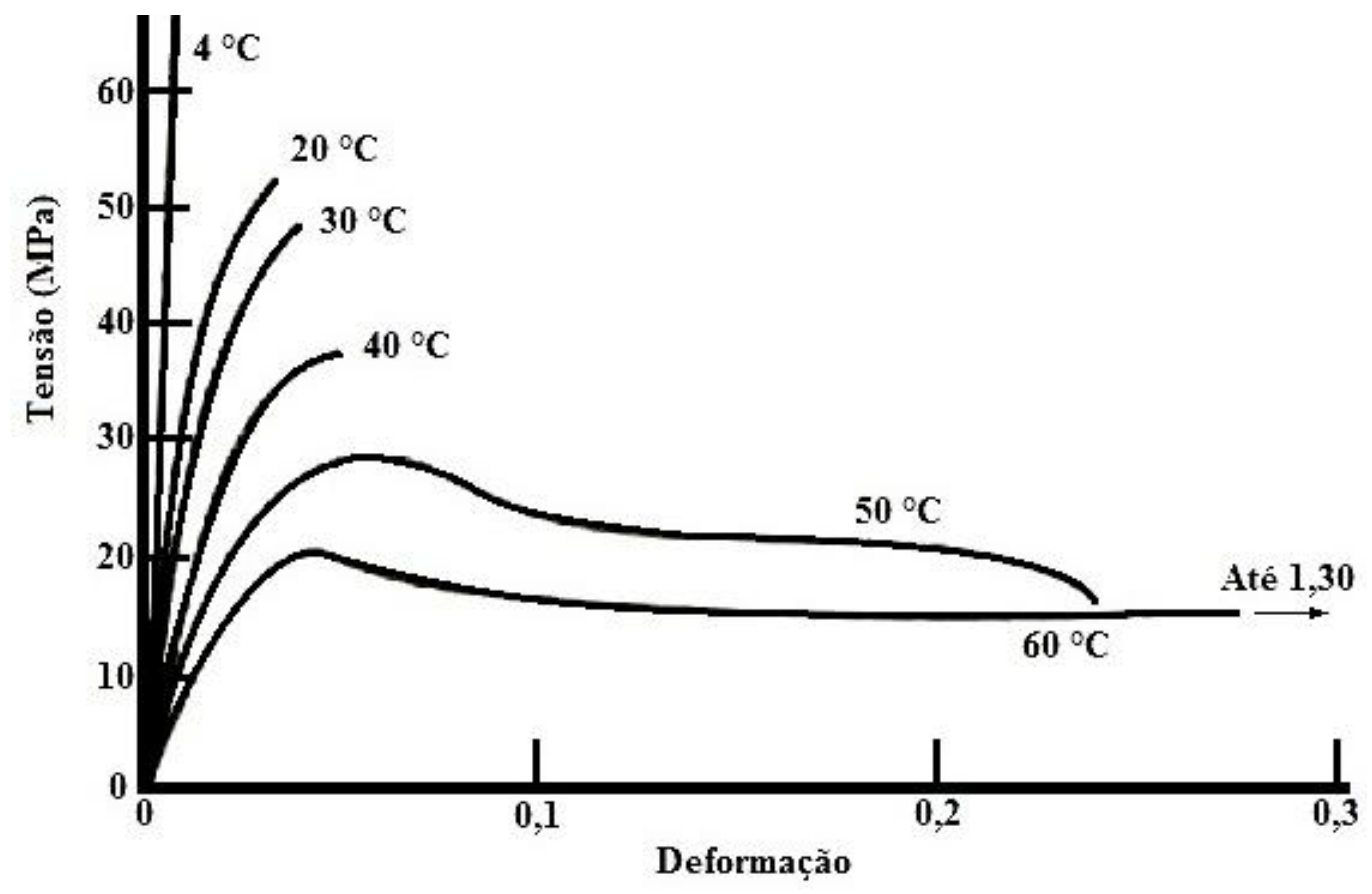

Figura 1 - Gráfico tensão-deformação do Poli (Metil Metacrilato) - acrílico - para várias temperaturas. (Adaptado de CALLISTER, 2008).

Os frascos e embalagens devem possuir os símbolos de identificação dos plásticos recicláveis, segundo a norma da ABNT NBR 13230 - "Embalagens e acondicionamentos plásticos recicláveis - identificação e simbologia", a qual é ilustrada na Figura 1.

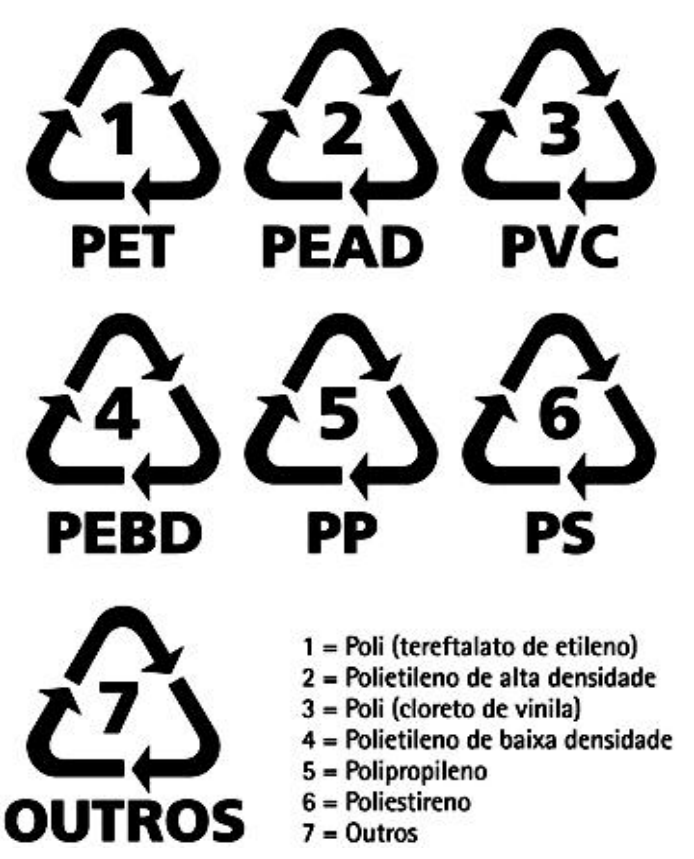

Figura 1 - Símbolos de identificação dos plásticos. (QUARTIN, 2008). 


\subsection{Processo de sopro}

Miranda (2011) afirma: “A compreensão das etapas que compõem a trajetória da préforma à garrafa é alvo de poucos estudos". Entretanto, é sabido que buscar o entendimento e o aprimoramento dos processos de fabricação acarretam na otimização do uso de insumos e matéria-prima, conservando - assim - o meio-ambiente.

O processo de sopro é uma tecnologia dedicada à obtenção de peças ocas de paredes finas (MIRANDA, 2011). O processo consiste no aquecimento de uma pré-forma acima da temperatura de transição vítrea, em seguida a mesma é posicionada entre moldes, inflada sofrendo estiramento e, finalmente, o frasco formado é resfriado e retirado do equipamento, conforme pode ser observado na Figura 2.

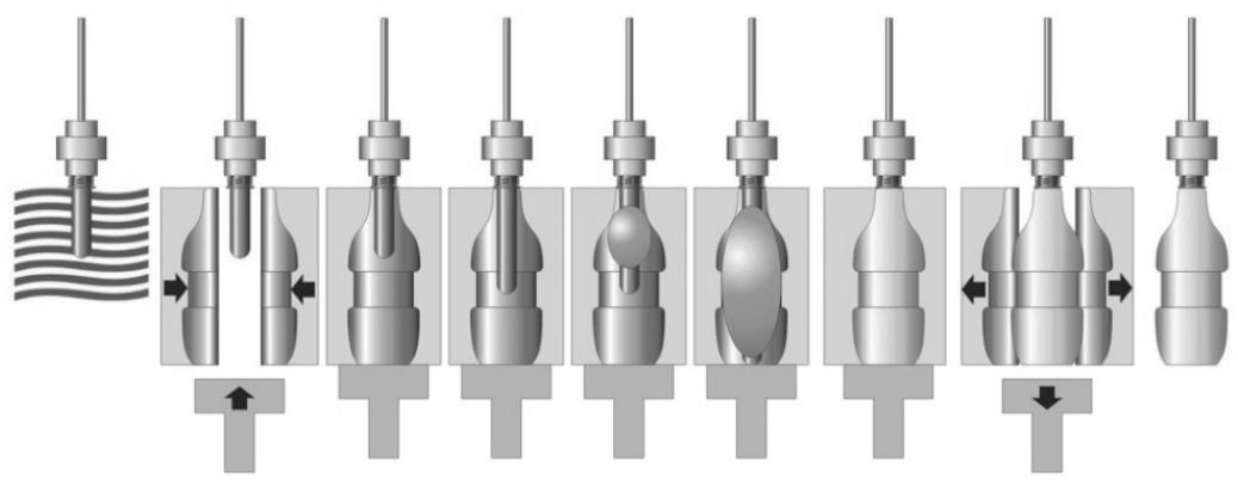

Figura 2 - Processo de Sopro. (MIRANDA, 2011).

\subsection{Degradação do PET}

Segundo Canevarolo Jr. apud Santos (2008), a degradação é um conjunto de reações que envolvem a quebra das ligações primárias da cadeia principal do polímero, ocasionando alterações na estrutura química e redução da massa molar, além de - obviamente - originar a formação de novas cadeias.

Degradação Térmica: A degradação térmica do PET começa a partir dos $300{ }^{\circ} \mathrm{C}$ com a formação de oligômeros cíclicos que acabam se decompondo quando a temperatura ultrapassa os $400{ }^{\circ} \mathrm{C}$, onde os produtos resultantes desse aquecimento - sem água e oxigênio - são representados na Figura 3. (HOLLAND et al. e GARCIA et al. apud SOARES JÚNIOR, 2010).

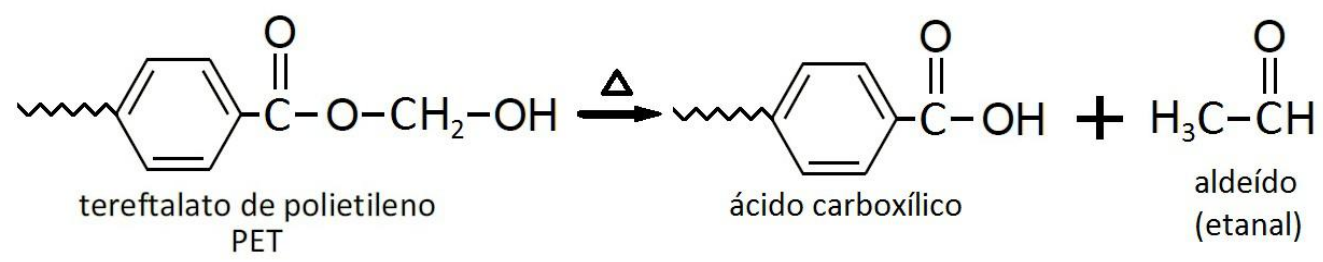

Figura 3 - Degradação Térmica do PET na ausência de $\mathrm{H}_{2} \mathrm{O}$ e $\mathrm{O}_{2}$. (SANTOS, 2008). 
Degradação Química: A principal degradação química do PET é através da hidrólise, mas - em condições de temperatura ambiente - a mesma só compromete a estrutura molecular da resina quando há a presença de catalisadores como ácidos fortes, bases fortes ou fenol. A exposição à água em temperaturas acima de $180{ }^{\circ} \mathrm{C}$ ou água quente por período prolongado também ocasionam a hidrólise, que é uma reação dada pela quebra de uma molécula qualquer por outra de água. (OLIVEIRA, 2006; SANTOS, 2008).

\subsection{Caracterização do problema}

Em visitas técnicas à Brasiaço Indústria e Comércio Ltda. foi relatado que mudanças repentinas no tempo (clima), como o início de chuva, podem gerar a ocorrência de produtos defeituosos consecutivos no processo de sopro, os quais acabam sendo rejeitados. As mudanças climáticas influem basicamente na umidade e temperatura ambiente, enquanto a variação da pressão atmosférica local é desprezível. Diante disso, criou-se o objetivo de investigar melhor tal fenômeno afim de compreender as interferências e ganhar previsibilidade para o ajuste dos parâmetros do processo de sopro.

\section{MATERIAL E MÉTODOS}

Após a polimerização do Tereftalato de Etileno e policondensação de estado sólido do Poli (Tereftalato de Etileno), a massa molar do PET ultrapassa $33.000 \mathrm{~g} / \mathrm{mol}$ e seu grau de polimerização situa-se entre 125 e 150 (número de unidades repetidas na molécula). A Figura 4 contém a fórmula química final do PET.

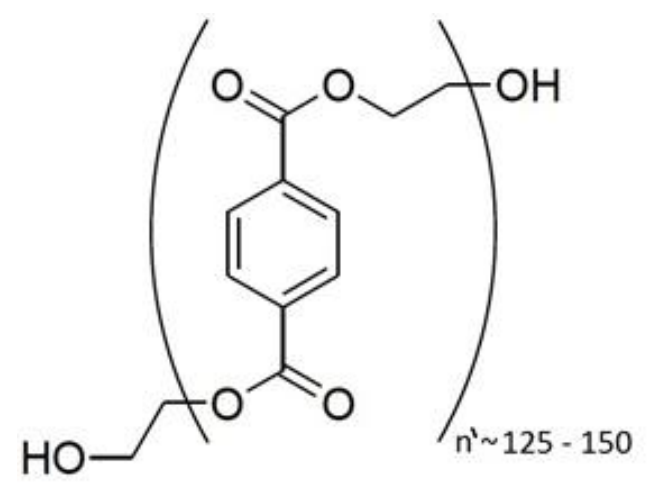

Figura 4 - Fórmula química do Poli (Tereftalato de Etileno).

As características mecânicas e a temperatura de transição vítrea do PET estão dispostas na Tabela 1 a seguir.

Tabela 1 - Características Mecânicas do PET.

\begin{tabular}{cccccc}
\hline $\begin{array}{c}\text { Gravidade } \\
\text { específica }\end{array}$ & $\begin{array}{c}\text { Módulo de } \\
\text { tração } \\
{[\mathrm{GPa}]}\end{array}$ & $\begin{array}{c}\text { LRT } \\
{[\mathrm{MPa}]}\end{array}$ & $\begin{array}{c}\text { Limite de } \\
\text { escoamento } \\
{[\mathrm{MPa}]}\end{array}$ & $\begin{array}{c}\text { Alongamento } \\
\text { na ruptura [\%] }\end{array}$ & $\begin{array}{c}\text { Temperatura } \\
\text { de transição } \\
\text { vítrea }\end{array}$ \\
\hline $1,29-1,40$ & $2,80-4,10$ & $48,3-72,4$ & 59,3 & $30-300$ & $75^{\circ} \mathrm{C}$ \\
\hline
\end{tabular}

Fonte: Adaptado de Modern Plastics Encyclopedia apud Callister, 2008. 
A pré-forma utilizada possui 19 g e geometria ilustrada na Figura 5. Já a forma final possui a mesma massa, volume interno de $140 \mathrm{ml}$ e pode ser vista na Figura 6.

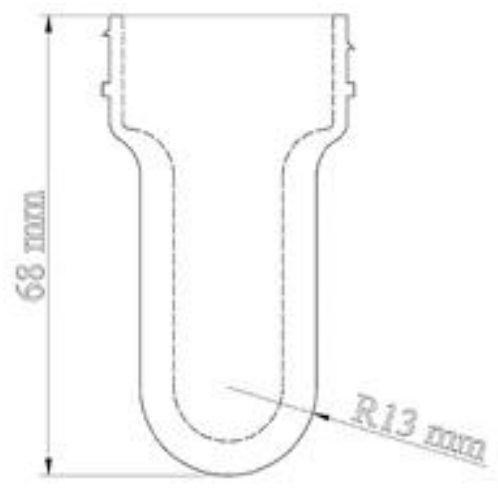

Figura 5 - Pré-forma.
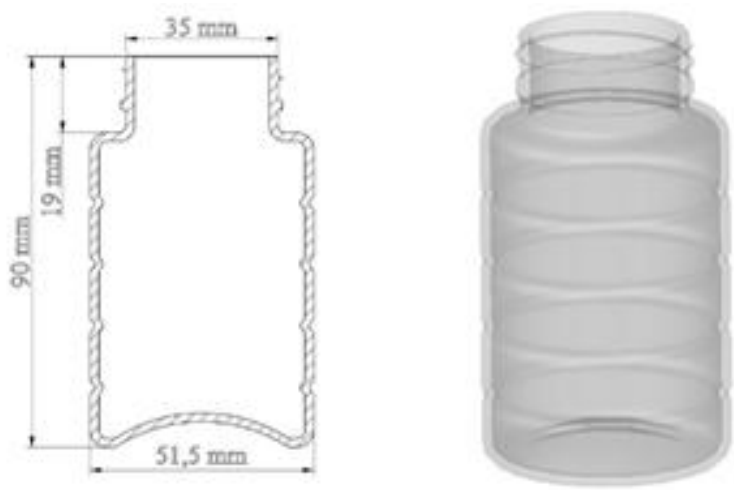

Figura 6 - Forma final - Frasco.

\subsection{Métodos}

As variáveis de estudo, temperatura e umidade ambiente, foram escolhidas baseando-se nos desafios enfrentados pelos técnicos da Brasiaço Ltda. no reajuste dos parâmetros do processo de sopro ao longo dos dias. Estas condições variam simultaneamente, o que dificultou até então a identificação intuitiva da influência de cada no processo.

A priori, foi definido a realização de análise amostral de dois lotes de produção, sendo um com umidade relativa entre 68 e $100 \%$ e o segundo entre 35 e $67 \%$. A definição do tamanho da amostra foi feita de acordo com a norma ABNT-NBR-5426/1985. Foi adotado um plano de amostragem simples com o nível de inspeção III para um lote de 400 unidades, resultando na Tabela 2.

A Tabela 2, abaixo, trata do Nível de Qualidade Aceitável (NQA) para que um lote de produção seja aceito. Defeitos de nível crítico são aqueles que aniquilam a funcionalidade do produto, enquanto os estéticos permitem a funcionalidade apesar da falha no processo.

Tabela 2 - Plano de amostragem Simples.

\begin{tabular}{|c|c|c|c|c|c|}
\hline \multirow{3}{*}{$\begin{array}{l}\text { Tamanho do lote } \\
\text { de inspeção (un) }\end{array}$} & \multirow{3}{*}{$\begin{array}{l}\text { Tamanho da } \\
\text { amostra (un) }\end{array}$} & \multicolumn{4}{|c|}{ NQA } \\
\hline & & \multicolumn{2}{|c|}{ 1,0 (crítico) } & \multicolumn{2}{|c|}{ 6,5 (estético) } \\
\hline & & Ac & $\mathrm{Re}$ & Ac & $\mathrm{Re}$ \\
\hline 281 a 500 & 80 & 2 & 3 & 10 & 11 \\
\hline \multicolumn{6}{|c|}{ Ac - Número de peças defeituosas (ou falhas) que ainda permite aceitar o lote; } \\
\hline
\end{tabular}

Fonte: Adaptado de ABNT-NBR-15395:2006. 


\section{RESULTADOS E DISCUSSÃO}

Foram avaliados lotes em dias diferentes para que fossem atendidas as condições ambientes previamente definidas. No primeiro dia a temperatura ambiente marcava $28{ }^{\circ} \mathrm{C}$ e a umidade relativa do ar era de $51 \%$. No segundo dia a temperatura ambiente era de $22{ }^{\circ} \mathrm{C}$ e a umidade registrada foi de $77 \%$. As medições das condições ambientes foram medidas com o termo higrômetro ilustrado na Figura 7.

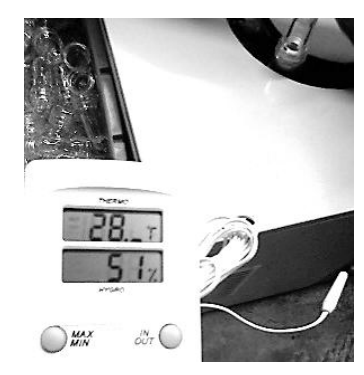

Figura 7 - Termo higrômetro.

\subsection{Primeiro dia}

A pressão de trabalho e de sopro estavam ambas ajustadas em $1 \mathrm{MPa}$, enquanto a temperatura média na estufa de aquecimento era de aproximadamente $153{ }^{\circ} \mathrm{C}$. O lote foi aceito com apenas uma peça defeituosa em nível crítico dentre duas aceitáveis e duas em nível estético dentre 10 aceitáveis, lembrando que foram avaliadas 80 amostras.

\subsection{Segundo dia}

No segundo dia a temperatura ambiente era de $22{ }^{\circ} \mathrm{C}$ e a umidade registrada foi de $77 \%$. Entretanto, utilizando-se exatamente os mesmos parâmetros de processo do dia anterior, o lote foi aceito com apenas um defeito estético a mais. Em seguida, verificou-se a temperatura de $65{ }^{\circ} \mathrm{C}$ na pré-forma após o aquecimento, ou seja, estava abaixo da temperatura de transição vítrea encontrada na literatura. Uma explicação é o PET utilizado ter menor grau de polimerização que o descrito na literatura.

\subsection{Análise psicrométrica}

A carta psicrométrica utilizada foi calculada através de software desenvolvido pelo grupo de refrigeração da UFMG, o Cartapsicrom.xls, tendo como dado de entrada a altitude do local, aproximadamente, $781 \mathrm{~m}$.

A análise psicrométrica de ambas condições ambientes demonstrou que apesar de um dia a umidade relativa ser de $51 \%$ e em outro $77 \%$, a umidade absoluta do ar era, respectivamente, 0,013 e $0,014 \mathrm{~kg} / \mathrm{kg}$. Ainda que a umidade relativa maior fosse $47 \%$ maior que a menor, a umidade absoluta maior era apenas $7,7 \%$ maior que a menor, devido às diferenças de temperatura em cada dia e, consequentemente, à capacidade do ar de absorver maior quantidade de água em temperaturas maiores. 
Com tais valores de umidade absoluta é evidente que na região de aquecimento da préforma, onde possui temperaturas acima de $150{ }^{\circ} \mathrm{C}$, a umidade relativa será extremamente baixa. Para critério de comparação, uma umidade absoluta de $0,014 \mathrm{~kg} / \mathrm{kg}$ resulta em uma umidade relativa de aproximadamente $17 \%$ a $50{ }^{\circ} \mathrm{C}$.

\subsection{Imersão em água}

Ainda no segundo dia, o autor especulou sobre a não influência da umidade no processo de sopro e a necessidade de monitorar apenas uma condição. Então, foi proposto a imersão de 3 pré-formas em água na temperatura ambiente durante - respectivamente - 10 segundos, 2 minutos e 5 minutos. Mesmo com um contato mais íntimo com a água que o tido normalmente através do ar, os resultados não apresentaram nenhuma alteração, podendo assim ser descartada a hipótese da umidade relativa do ar ter influência sobre o processo de sopro. Outrossim, tal processo ocorre a temperaturas máximas próximas a $150{ }^{\circ} \mathrm{C}$, inferiores às temperaturas de degradação térmica $\left(>400^{\circ} \mathrm{C}\right)$ e de degradação química por hidrólise $\left(>180{ }^{\circ} \mathrm{C}\right)$.

\section{CONCLUSÃO}

Foi evidenciado que apenas a temperatura ambiente desempenha papel relevante no processo de sopro estudado. Uma vez que o material tende a ficar em equilíbrio térmico com o ambiente, há variação na quantidade calor que deve ser fornecido ao material para atingir a temperatura de transição vítrea e, consequentemente, a necessidade de reajustar os parâmetros do equipamento. Por fim, foi sugerido à empresa Brasiaço posicionar um termômetro próximo ao processo e realizar o registro das temperaturas ambientes e de processo, afim de obter previsibilidade e maior independência em relação ao know-how de poucos profissionais.

\section{AGRADECIMENTOS}

Agradecemos à Brasiaço Indústria e Comércio Ltda por abrir suas portas e permitir que esta pesquisa fosse realizada.

\section{REFERÊNCIAS}

CALLISTER JR., William D. Ciência e engenharia de materiais: uma introdução. 2008. Livros Técnicos e Científicos Editora S.A., $7^{\mathrm{a}}$ ed. Rio de Janeiro, RJ.

CANEVAROLO JR, Sebastião V. Ciência dos Polímeros: um texto básico para tecnólogos e engenheiros. 2006. Artliber Editora Ltda., $2^{\mathrm{a}}$ ed, São Paulo, SP.

MIRANDA, Carlos Alberto Silva de. Simulação do processo de sopro de garrafas de poli (tereftalato de etileno) a partir de pré-formas disponíveis através do método de elementos finitos. 2011. Tese (Doutorado) - Universidade Federal de Ouro Preto, Escola de Minas - Rede Temática em Engenharia de Materiais, Ouro Preto, MG.

OLIVEIRA, Jackson Araújo de. Oligomerização e policondensação em estado fundido do Poli (Tereftalato de Etileno) - estudo experimental e de modelagem da curva de distribuição de pesos moleculares. 2006. Tese (Doutorado) - Universidade Federal do Rio de Janeiro, COPPE, Rio de Janeiro, RJ. 
SANTOS, Antônio Cláudio dos. Estudo da Reciclagem o Poli (Tereftalato de Etileno) PET pós consumo e de suas propriedades, quando submetido à radiação ionizante. 2008. Dissertação (Mestrado) - Instituto de Pesquisa Energéticas e Nucleares Autarquia Associada à Universidade de São Paulo, São Paulo, SP.

SOARES JUNIOR, Aldo Batista. Produção do Poli (Tereftalato de Etileno) modificado com glicerol e derivados. 2010. Dissertação (Mestrado) - Universidade Federal do Rio de Janeiro, COPPE, Rio de Janeiro, RJ.

QUARTIM, Elisa. Rotulagem ambiental II. Embalagem Sustentável, 2008. Disponível em: $<$ http://embalagemsustentavel.com.br/2008/09/10/rotulagem-ambiental-ii/>. Acesso em: 25 fev. 2014. 